\title{
The Analysis of the Impact of the New Silk Road with Logistic for Economic Growth
}

\author{
Yu dejun \\ Professor, Oxbridge College, Kunming University of Science and Technology \\ Kunming,China \\ E-mail: huiyi2015hy@163.com
}

\begin{abstract}
The Northwest of China in the Silk Road Economy is an important window for China to communicate with East and Central Asia, with the strengthening of the logistics industry, the smooth flow of trade is being promoted, the economic is growing,and the cooperation between China, East and Central Asian countries is deepening. Based on the foundation of the mechanism which is about the development of the logistics and the growth of the economic, this article apply the mode that the panel data fixed while the effects coefficient variable, the cargo, freight turnover and logistics industry are being used as substitution index, and select five provinces in the economic belt from 1952 to 2012 as a sample, to study the contribution that the development of the Silk Road Economic Zone Logistics to the economic growth. Studies have shown that the development of the Silk Road Logistics in Northwest Economic Zone has a greater contribution to the economic growth, while the contribution that the cargo, freight turnover and logistics industry to the economic growth is different from areas.
\end{abstract}

Keywords-The new Silk Road; the logistics of economic zone; analyze the impact

\section{THE ANALYSIS OF THE INTERNAL MECHANISM BETWEEN THE DRIVING FACTORS OF LOGISTICS DEVELOPMENT AND ECONOMIC GROWTH.}

According to the existing research found that the main element of logistics development is being constituted by the social efficiency of logistics and logistics to meet the social needs of the extent and size of the logistics activities create value, the relevant indicators can be replaced by freight turnover, cargo and logistics added value. When the freight turnover and cargo growth, the social freight demand will increase, the investment and construction about the public facilities like increase the transportation will be promoted by the government and enterprises, thereby can release the potential demand of the logistics, improve the logistics operation efficiency, drive the development of the logistics industry, and the improve of the logistics industry can encourage the governments and businesses to led to further deepen of the logistics business, extend the value of the flow of logistics on the foundation of the traditional business like transportation, warehousing, transportation, etc., innovate the logistics services, promote the rationalization of the logistics industry structure, drive the development of the logistics industry. Therefore, we choose freight, freight turnover and logistics industry to explore the internal mechanism between the development of logistics and economic growth. Cargo, freight turnover are the derived form which are generated with the activities of social spending(productive consumption and life consumption) demand, when the economic growth become a potential social consumer demand, logistics demand growth, and then cargo, freight turnover growth, while if the supply of social logistics lags behind the growth of logistics demand will strict the growth of economic. On the one hand the growth of the social economic can expand logistics demand, and the higher the level of the regional economic development,the more active of the regional economy, the demand of the raw materials, semi-finished and finished products in circulation is more higher, which can promote cargo and freight turnover growth more further, on the other hand the logistics subsystem which is in the social and economic systems has a positive feedback effect for economic growth, when the regional cargo growth, the number of logistics services for the regional economy is increasing, the gap area in the consumption is bridging, and the economic growth is promoting; when the regional freight volume increase, the logistics efficiency can be improved, the economic ties between the regions, the industry is being more closely, the more potential social consumer demand is being released, the greater the positive impact on regional economic growth.

The mechanism relationship between cargo, freight turnover and economic growth can be analyzed from two-dimensional, first, the economic growth can promote the social spending, and then the growth of cargo volume and freight turnover (logistics demand growth) is being further promoted, the transmission mechanism can be expressed as:economic growth $\uparrow$ - social consumption growth - cargo, freight turnover growth $\uparrow$. The social consumption activities is worked as a media between economic growth and freight, freight turnover, it shows that economic growth indirectly promote freight, freight turnover growth, but at this transmission mechanism, the indirect effects is a irreversible process.Second, the cargo, freight turnover growth, if the supply of the logistics system is in shortage, the capacity of logistics is being lower and leads to poor transport, the result is the backlog of goods and the limit of the increased needs of social spending,thus restricting the growth of the regional economy; if the logistics supply and the capacity of supply are excess, the result is the waste and the idle of the social logistics resources, meanwhile there will be a corresponding costs, this will leads to the indirect constraint on economic growth. Thus, the prerequisite for the cargo, freight turnover to promote economic growth is 
reached a relatively balanced state between the needs and supply of the logistics, that is when the freight, freight turnover growth, the corresponding supply of logistics would be enhanced and the logistics system would be improved, and then boost economic growth, the transmission mechanism can be expressed as: cargo, freight turnover $\uparrow-$ (Logistics demand growth = supply volume growth) $\uparrow-$ Economic growth $\uparrow$. The social consumption activities and the supply of logistics play a main role as an intermediary in the mechanism relationship between Cargo.

For the supply of social logistics system lags behind the increase of the demand of the cargo, freight turnover in the short-term, $\mathrm{P}$ '( the price of the freight) is rising, and then there will be more market investment for the supply of the logistics, gradually, the logistics infrastructure, logistics system being improved, the amount of the supply of the logistics being increased, and the curve of the supply transition from Sw1 to Sw2, reached a new balance between cargo, freight turnover demand and supply of logistics, in this process, $\mathrm{P}$ 'gradually reduced.With the rising of the products prices and the decreasing of the cost of the freight rates, the producer increased the supply of the products by degrees, the curve of the supply gradual transition from the $S 1$ to $S 2$, in the process, the potential gap of the raw materials, semi-finished and finished products freight when the regional economic development necessary is generally being bridged, the economic growth is being promoted, a positive cycle between the logistics development and economic growth is being formed.

\section{THE ANALYSIS OF THE IMPACT of THE DRIVING ELEMENT OF LOGISTICS DEVELOPMENT HAVE FOR ECONOMIC \\ GROWTH}

The mechanism relations between the cargo, freight turnover and economic growth, which are the driving element of logistics development, through the transmission mechanism to work. There is a trend diagram which is made by the analysis of the relations between the cargo, freight turnover and economic growth in five northwestern provinces which are in the Silk Road.

The change trend of the cargo, freight turnover growth and economic growth keep consistent in the five northwestern provinces, from1952 to 1971, they growth together or fall together, and in 1963, all of them in the rebound of the valley around the same time, the main reason is that in 1959-1961 our country was suffer the three years of natural disasters, the development of the industrial, agriculture and tertiary industry in a stagnation condition, and the shrink of the economic activity leads to the reduce of the production and the demand of spending, thus leads to the curve of the cargo, freight turnover growth and economic growth formed a common decreased trend. After 1972, cargo, freight turnover and economic growth formed a common rising trend. Observed the change trends of the freight, cargo turnover and GDP from the entire graph, it shows that there is a certain relevance between the cargo, freight turnover and economic growth. The Table below was got by apply the statistical software SPSS18. 0 to analysis the correlation between cargo, freight turnover and GDP data in five northwestern provinces from 1952 to 2012。

From Table 1, the correlation coefficient of the freight, freight turnover and economic growth in five northwestern provinces are greater than 0.8 , so between them is a positive correlation, and they change to the same direction. Wherein, the correlation of cargo with economic growth is strong in Gansu, Xinjiang Autonomous Region and Shanxi, and also strong in Qinghai, Ningxia Autonomous Region ; the correlation of freight turnover and economic growth is strong in Qinghai, Xinjiang and Shanxi three regional, and also strong in Gansu and Ningxia. The added value of logistics industry is a part of e regional economic growth, it has a direct contribution on economic growth, the Figure 3 was got by calculating the correlation between the added value of logistics industry in five northwestern provinces from 1952 to 2012 with the GDP trends, shown in Figure 3: Figure 3 shows that after the 1949, our country implemented a series of economic development plans, the "a wthfive-year plan" which was implemented after 1952 is one of them, our country's industry, light industry, agriculture, commerce and transportation got rapid development, these formed the strong growth trend of the GDP and the added value of logistics industry in 1952-1954. With the rapid development of industrial infrastructure, based on the 1952, GDP and logistics industry continued growth to around 1959. In 1959-1961, for the three years of natural disasters, both of them fallen in valley, since the 1976, the logistics industry and GDP are intersect and are synchronized into an upward trend.From the entire Figure, the trends of them are basically the same.By analysis the correlation of the historical data between the logistics industry and GDP in 1952-2012。

\section{THE CONCLUSIONS AND RECOMMENDATIONGS}

This paper is to study the contribution that the Silk Road economic belt of the regional logistics driver elements have on the economic growth. The study found that between driver elements of logistics development and economic growth have a strong correlation, the development of logistics has a positive role in boosting economic growth, but the contribution is different from areas. According to the findings, some policy recommendations are being put forward:

First, to accelerate the construct of logistics infrastructure in the Northwest of the Silk Road economic belt,and promote cargo, freight turnover growth. On the basis of the current level of urbanization, it is a good way to promote freight, freight turnover growth by increasing urbanization and the rate of urbanization to improve potential logistics demand. In 2012,the urban population in Gansu Province was $38.7 \%$, Ningxia Autonomous Region was $50.67 \%$, Xinjiang was $43.98 \%$, Qinghai was $47.44 \%$, Shanxi was $50.02 \%$, and compare to the average urbanization rate of $80 \%$ in developed countries, there is a large gap.In the future, with the development of the social and the urbanization rate, the gap between urban and rural areas will be reduced, the social logistics needs in Northwest will be improved further, and the cargo, freight turnover growth will be promoted, then boost the 
regional economic growth. The government needs to accelerate the pace of urbanization and increase social demand for logistics. In addition, for the urbanization level among the five northwestern provinces have differences, in future the demand for logistics will be different from each other, so it is necessary to develop transport facilities, especially railway transport and strengthen Northwest Opening degrees, thus form a network through the five northwestern provinces, and also to link East, Central Asia together,by this way to promote the factors of production flow. Therefore, expand the scope of economic radiation in Northwest Silk Road economic belt.

Second, deepen the logistics business value chain, and to encourage innovate in logistics services business, reduce the logistics revenue, improve logistics industry. The results proved that the main cause of stimulating economic growth is the driving element of the development of logistics, that is logistics industry.According to increase the logistics industry method to calculate, the two important inputs in it are the workers compensation and government taxes, so the effective tax cuts policy can reduce the operating costs of the logistics industry, and lead to improve the logistics industry, thus promote economic growth. In addition, encourage the innovation of the logistics services business and promote the transformation of business, deepen the chain of logistics value, increase the development of distribution, processing, logistics, information services and financial services business, with the innovation of the logistics business service, the logistics industry is being improved and the economic growth is being promoted.
Third, encourage the specialization of logistics industry to improve logistics industry. With the improving of the level of logistics, the specialization of logistics service is being promoted, the logistics efficiency is being enhanced, the logistics industry is being increased, and the regional economic growth is being boosted. The Government should actively guide the development of third-party logistics, provide the necessary policy and financial support, and encourage regional non-logistics companies change their own logistics business into social logistic, enhance their professional level, thus get the lower costs and the enhancement of social logistics industry, therefor stimulate the growth of the Silk Road Northwest economy.

\section{REFERENCES}

[1] Wang Zhili. Geography of logistics economy [M]. Beijing Electronics Industry Publishing House, 2012 (12).

[2] Liu Binglian. Analysis and Forecast Method of Logistics Demand [J]. China Soft Science, 2004 (5): 66-73.

[3] Liquan Xi, Jin Fenghua. The build and applied research of regional logistics attraction and status model [J]. Economic Geography, 2010 (10): 16-24

[4] Jia Haicheng. The analysis of the association between economic development and regional logistics industry $[\mathrm{J}]$. Technology Progress and Policy, 2012 (12): 44-49.

[5] Liu Nan. Relationship between Modern Logistics and Economic Growth - Based on examples of Zhejiang Province [J]. Management Engineering, 2007 (1): 151-153.

[6] Li Jicai, Wu Jian. Interaction between Logistics Industry and Economic Growth [J]. East China Economic Management, 2011 (3): 6-8. 